\title{
O CARÁTER DE PUBLICIZAÇÃO DA LEITURA NA OBRA DE COMÊNIO
}

\author{
Ana Maria Esteves Bortolanza*
}

\begin{abstract}
RESUMO
Este artigo tem por objetivo explicitar o caráter de publicização da leitura em Comênio. Para isso, analisa os condicionantes sociopolíticos, históricos e religiosos que permeiam as questões didático-pedagógicas pensadas pelo grande pedagogo. Em sua obra Didáctica Magna - Tratado da Arte Universal de Ensinar Tudo a Todos, o caráter de publicização da leitura responde às necessidades que as novas relações sociais passaram a exigir em consequência da nova forma de produção da sociedade capitalista. Em sua didacografia, a nova arte de ensinar comeniana propôs conteúdos que evidenciam o caráter de publicização da leitura.
\end{abstract}

Palavras-chave: Leitura. Publicização da leitura. Comênio. Didáctica Magna.

\section{RÉSUMÉ}

Cet article vise à expliciter le caractère de publicisation de la lecture des oeuvres d'Comenius. C'est pouquoi nous avons cherché d'apprendre les conditionnements sociopolitiques, historiques et réligieux qui s'interpénètrent avec les questions didactiques et pédagogiques pensées par ce grand pédagogue. Comenius et son ouvrage Didactica Magna - Traité de l'Art Universel d'Enseigner Tout à Tous, le caractère de publicisation de la lecture répond aux exigences des nouveaux rapports sociaux créés par le nouveau mode de production. Le nouveau art d'enseigner coménien propose des contenus qui mettent en évidence le caractère de publicisation de la lecture.

Mots-clés: Lecture. Publicisation de la lecture. Comenius. Didactiva Magna.

\footnotetext{
* Doutora pela Universidade Estadual Paulista "Júlio de Mesquita Filho", (UNESP), no Programa de Pós-Graduação em Educação. Docente do Programa de Pós-Graduação em Educação da Universidade de Uberaba (Uniube). Pós-Doutorado em andamento na Universidade de Évora, Portugal. E-mail: amebortolanza@uol.com.br
} 
Este artigo analisa o caráter de publicização da leitura em Comênio, no contexto das relações sociohistóricas em que sua obra foi produzida. Para essa análise, primeiramente, situamos o autor e sua obra na transição entre a sociedade feudal e a sociedade burguesa, em meio às profundas transformações sociais na Europa Central e na Boêmia, século XVII, período em que viveu e produziu uma de suas mais importantes obras, a mais conhecida sem dúvida, Didáctica Magna - tratado da arte universal de ensinar tudo a todos. Em Comênio e sua obra, o caráter de publicização da leitura se expressa ao cumprir uma nova função social, respondendo às necessidades que as relações sociais passaram a exigir em consequência da nova forma de produção da sociedade burguesa.

A leitura, como parte do fenômeno da linguagem, é para Bakhtin (1992) uma criação humana em movimento permanente, movimento esse que é dado pelo conjunto das relações sociais dos homens num determinado momento e espaço. Esse caráter histórico da linguagem é fundamental para a compreensão da leitura e seu caráter de publicização como prática social. Portanto, apreender a linguagem e suas formas de manifestação significa resgatar o momento histórico em que essa linguagem se produziu, procurando explicitar sua função social.

\section{Comênio: entre feudalismo e capitalismo}

Autor em uma fase de transição do feudalismo para o capitalismo, Comênio refletiu em sua obra as contradições entre o velho e o novo, as necessidades de seu tempo, as inquietações do novo homem que estava nascendo. Sua história de vida e a história de seu tempo revelaram uma nova sociedade emergindo: a sociedade capitalista. O pensamento pedagógico de Comênio expressou coerentemente as mudanças que ocorreram nas ciências, na cultura, o novo modo de produção, o caráter de universalidade das novas relações sociais na Europa Central e na Boêmia daquela época. A ruptura do modo de produção feudal e a emergência do novo modo de produção capitalista trouxeram consigo uma nova ordem social, política, cultural e religiosa. Alterações graduais e desiguais minaram a velha estrutura social, abrindo caminho para a modernidade. 
Comênio representa essa transição em que o velho e o novo coabitaram, o velho se esgotando, o novo incorporando o velho... nem Idade Média nem Idade Moderna. Nesta passagem, novas práticas e relações sociais se estabeleceram, emergindo uma nova classe social: a burguesia. A burguesia foi ocupando espaços em direção a uma vida mais racional: a valorização do homem como indivíduo capaz de transformar a realidade que o circundava; a noção de progresso capaz de substituir o paraíso celeste pela felicidade terrena; a sobreposição das ciências modernas sobre o saber medieval inquestionável; a utilização do conhecimento dos fenômenos naturais substituindo as crenças no sobrenatural; o pensamento divergente superando a mentalidade dogmatizada.

A necessidade de um novo saber em que a cooperação era fundamental se impôs. Os homens precisavam produzir conhecimentos que respondessem às necessidades da sociedade, mas, sobretudo, comercializar esses conhecimentos. As mudanças materiais que se operavam, produziram também novas necessidades espirituais: livre interpretação das Sagradas Escrituras, outras formas de religiosidade, de fé e de esperança, de conhecimentos úteis para a vida prática, diferentes artes para atender à vida concreta dos homens. Em síntese, o século XVII foi o século das revoluções, das mudanças que as velhas e frágeis estruturas das monarquias europeias não suportaram. A força da nova classe produtora lutava pela hegemonia e venceria primeiramente na Inglaterra, lugar em que se desenvolvia a forma mais avançada de capitalismo.

Na Boêmia, o desenvolvimento das forças produtivas deu-se de forma diferenciada de outros países da Europa. A Guerra dos Trinta Anos, na primeira metade do século XVII, retardou a passagem do feudalismo para o capitalismo, fazendo com que a sociedade boêmia se constituísse predominantemente de elementos da velha ordem feudal. Os senhores ocupavam terras que deixaram de ser trabalhadas durante a guerra, a mãode-obra assalariada encarecia em virtude da redução da oferta de trabalho. As relações feudais entre senhores e servos acabaram se fortalecendo, contrariamente ao que acontecia nos países da Europa Ocidental.

Vivendo naquele momento histórico de profundas mudanças sociais, a postura de Comênio revelou, de um lado, a visão moderna do pensamento burguês revolucionário, do espírito universal, do homem- 
centro do mundo; e, de outro, do homem feudal voltado para Deus Criador e Senhor do Universo. Situado nesse momento de contradições e incertezas, o pensamento pedagógico comeniano espelhou a imagem dos novos tempos, em que as artes mecânicas substituíram a natureza e, as novas formas de trabalho e os novos métodos das ciências experimentais condicionaram sua arte de ensinar.

\section{Opera Didactica Magna}

É a obra de Comênio que reúne os escritos a partir de 1630, com intuito inicialmente de oferecer à Boêmia liberta uma obra que lhe servisse de guia para sua reconstrução. A apresentação da obra é uma verdadeira profissão de fé de seu autor, pois se trata de uma declaração pública solene de afirmação de suas convicções pedagógicas e religiosas: Didactica Magna, tratado da arte universal de ensinar tudo a todos (COMÊNIO, 1985, p.43). A arte de ensinar resulta tanto do caráter religioso e da preocupação com a educação da Unidade dos Irmãos, quanto do novo modo de produção nas manufaturas do mundo burguês.

O autor refere-se à obra como "tratado", palavra que, segundo Araújo (1994, p. 22), associava-se "às novas descobertas do fazer de artesãos, mecânicos, tipógrafos e outros que estavam envolvidos nas artes a princípio consideradas como indignas de homens letrados e cultos". A separação entre o fazer e o saber foi gradativamente superada pelo novo modo de produzir a existência que já não comportava o ócio cultivado pela nobreza na sociedade feudal. Ao definir sua obra como um "tratado da arte de ensinar tudo a todos", Comênio marcou sua postura ideológica, opondose à cultura dominante, medieval e clerical, baseada na metafísica.

A palavra "arte", contrariamente ao sentido da palavra tratado, que limitava seu significado ao conotar a arte de quem e para quem "produzia o conhecimento por experiência", buscou legitimar o novo saber, baseada nas artes mecânicas em contraposição às artes liberais medievais. Ao designar um método universal a serviço de todas as artes, a arte comeniana ganhou um novo estatuto.

O pensamento pedagógico comeniano traçou um movimento universalizante, tendência da época, partindo em sua obra da educação para jovens até 24 anos, em que a ideia de "todo o mundo" traduz-se por escola, 
pois o que pretendia o autor era reformar a educação e, só posteriormente, na obra Pampaedia, pregaria a educação para toda a humanidade durante toda a vida.

A dimensão de universalidade, contida nos termos "todos, tudo e arte universal", que caracteriza sua obra, surpreendeu naquele momento, uma vez que não se tratava de mais uma arte de ensinar limitada. Para Comênio tratava-se de:

um processo seguro e excelente de instituir, em todas as comunidades de qualquer Reino cristão, cidades e aldeias, escolas tais que toda a juventude de um e de outro sexo, sem exceptuar ninguém em parte alguma, possa ser formada nos estudos, educada nos bons costumes, impregnada de piedade, e, desta maneira, possa ser, nos anos da puberdade, instruída em tudo o que diz respeito à vida presente e à futura, com economia de tempo e de fadiga, com agrado e solidez. Onde os fundamentos de todas as coisas que se aconselham são tirados da própria natureza das coisas; a sua verdade é demonstrada com exemplos paralelos das artes mecânicas; o curso dos estudos é distribuído por anos, meses, dias e horas; e, enfim, é indicado um caminho fácil e seguro, de pôr estas coisas em prática com bom resultado (COMÊNIO, 1985, p. 43).

"Ensinar tudo" não significava transmitir o conjunto de conhecimentos historicamente acumulados, pois que não "exijamos a todos o conhecimento de todas as ciências e de todas as artes [...] Com efeito, isso, nem, de sua natureza é útil, nem, pela brevidade de nossa vida, é possível a qualquer dos homens" (COMÊNIO, 1985, p. 145).

Comênio passa a indicar, em seguida, o modo pelo qual se realiza sua proposta de "ensinar tudo a todos". Primeiramente, qualifica o caminho escolhido como "excelente", aquele que excele, o melhor, e aquele no qual se pode confiar, que é certo, indubitável e eficaz, "seguro". Indica então o lugar em que as escolas deverão ser instituídas, "em todas as comunidades de qualquer Reino cristão, cidades e aldeias" (COMÊNIO, 1985, p.43). Reino cristão, uma vez que ele parte de sua concepção de homem como "a criatura de Deus perfeita" (COMÊNIO, 1985, p. 315), e a educação foram para o autor um meio de o homem atingir sua perfectibilidade, à 
semelhança do Criador. A afirmação "toda a juventude de um e de outro sexo, sem exceptuar ninguém em parte alguma" (COMÊNIO, 1985, p. 316) demonstra o pensamento universalizante que ele expressou na Pampaedia, obra em que estende a educação para toda a vida. A inspiração religiosa de Comênio ao lado de seu pensamento pedagógico são elementos indispensáveis para a compreensão de sua obra, pois a juventude dever "ser formada nos estudos, educada nos bons costumes", mas isso só é possível, se essa juventude estiver "impregnada de piedade", isto é, de devoção religiosa (COMÊNIO, 1985, p. 43).

Vivendo na fase de transição entre dois modos de produção, Comênio apropriava-se do novo conteúdo por meio da velha forma. $\mathrm{O}$ fim último do homem deixava de ser tão somente a vida eterna, alcançar o Paraíso Celeste, mas o paraíso, o homem o construiria na terra, na vida presente, no cotidiano, para isso a juventude devia ser "instruída" em tudo o que diz respeito "à vida presente e futura" (COMÊNIO, 1985, p. 43).

Nesta perspectiva, a obra de Comênio pode ser lida como expressão pedagógica da transição entre a Idade Média e a Idade Moderna, uma vez que contem elementos de ambas as fases e registra o momento em que o velho modo de ensinar foi substituído pela nova arte, assim o reflexo das manufaturas exigia também na produção intelectual "economia de tempo e de fadiga, agrado e solidez" (COMÊNIO, 1985, p. 43).

Para Comênio, os conteúdos a serem transmitidos para a juventude, como a instrução, a moral e a religião, eram inatos ao homem. Seguir o curso natural significava para o autor buscar "nosso estado primitivo e fundamental" (COMÊNIO, 1985, p. 101), isto é, a nossa essência, não corrompida pelo pecado, e assim alcançar "a providência universal de Deus" (COMÊNIO, 1985, p. 102), pois Ele é a força que possibilita ao homem cumprir a finalidade para a qual foi criado.

O novo caminho, pelo qual "os fundamentos de todas as coisas que se aconselham são tirados da própria natureza das coisas" (COMÊNIO, 1985, p. 43), constituía-se o verdadeiro guia para a formação do homem. Deve-se entender por "natureza" o próprio conhecimento historicamente acumulado que o homem constrói, portanto, uma natureza socialmente produzida pelos homens, na qual "a verdade é demonstrada com exemplos paralelos das artes mecânicas” (COMÊNIO, 1985, p. 43). 
Mesmo revelando uma postura conservadora em várias passagens de sua obra, como a memorização, a passividade do aluno e a centralização do professor, é o espírito renovador que prevalece na nova arte de ensinar comeniana. As marcas impressas da nova forma de trabalho, a natureza produzida historicamente, a observação e a experimentação, as artes mecânicas, a utilidade das coisas apontavam para uma educação democrática no sentido de popular. A proposta de popularizar a educação supunha, entre outras questões, a produção de livros em escala industrial e condições de acesso à leitura. Essa questão foi tratada por Comênio com objetividade e lucidez.

Em Ventilabrum Sapientiae, livro em que defende entusiasticamente a Didactica Magna das críticas recebidas, Comênio afirma que "aquelas coisas não foram escritas para os sábios, mas para despertar da letargia geral do sono profundo o povo" (COMÊNIO apud GASPARIN, 1994, p. 49). O autor reafirma sua intenção de democratização da educação ao declarar que escreve para "a massa que ainda dorme [...] que precisa ser acordada". Ao invés de iniciar definindo a didática, Comênio apresenta "os fundamentos e os fins últimos do homem sobre os quais ela se assentará, bem como os meios adequados para realizá-la”. Se os fins últimos do homem são eternos e universais, ele somente "podia propor uma didática de vida, isto é, universal, que atingisse todos os homens e os conduzisse, como novo instrumento de salvação, à plena realização junto a Deus" (GASPARIN, 1994, p. 50).

Como homem profundamente religioso, sua missão era espiritual, contudo, para realizá-la, precisava este grande pedagogo de servir-se de instituições como as escolas, que, segundo os Irmãos, não deveriam destinar-se somente ao clero e às elites. A Reforma colocava historicamente a necessidade de escolas para que o povo pudesse aprender a ler e assim ter acesso sem intermediários aos textos sagrados. As novas forças produtivas incorporavam, de certa forma, esse caráter religioso,pois, embora a arte de ensinar comeniana fosse "empresa humana, expressão do novo modo de vida material e cultural", não deixava de incorporar "o espírito religiosoeducacional e de universalidade dos Irmãos" (GASPARIN, 1994, p. 73). Estava posto o caráter de publicização da leitura na obra Didáctica Magna. 


\section{A publicização da leitura em Comênio}

Como transmitir os conteúdos que a nova arte de ensinar propunha? Para Comênio, a natureza deveria ser ponto de partida e modelo para a arte de ensinar. Num primeiro momento, a natureza "natural":

É certo, por isso, que também o homem foi feito, por natureza, apto para a inteligência das coisas, para a harmonia dos costumes e para o amor a Deus sobre todas as coisas [...] e é tão certo que as raízes daquelas três coisas se encontram nele quanto é certo que a cada planta foram dadas as raízes sob a terra (COMÊNIO, 1985 p. 102).

Os processos mecânicos, que são a imitação da natureza, ou seja, a própria natureza artificial, foram modelos e pontos de partida para a didática comeniana.

Primeiramente, o relógio que seduz pelo funcionamento perfeito da máquina com base no movimento do universo, pois: "inventou-se um instrumento capaz de reproduzir exatamente o movimento rotatório diário do firmamento e medir as horas" (COMÊNIO, 1985, p. 187). Do relógio, Comênio passou para a máquina tipográfica que representava para o autor "o novo protótipo da arte de ensinar, a expressão mais elaborada e definitiva da arte comeniana, uma criação puramente humana, social e histórica" (GASPARIN, 1994, p. 83).

No capítulo 32 de Didáctica Magna, em que se trata da "organização universal e perfeita das escolas', o autor comparou a organização da escola com a tipografia". Comênio confrontou a velha forma de ensinar com os trabalhos dos copistas de multiplicar os manuscritos através da escrita a pena, e a nova forma de ensinar com a arte da imprensa, enumerando as vantagens que a arte mecânica de multiplicar os livros proporcionava. Aqui se explicita o caráter de publicização da leitura.

Ao indicar a arte mecânica da imprensa, a tipografia como modelo da arte de ensinar, Comênio elegeu a nova forma de produção, uma vez que, de acordo com Gasparin (1994, p.87): 
a máquina, como expressão da nova forma de trabalho, iguala todos os homens no processo de produção tanto material quanto intelectual [...] o manuscrito é o símbolo de um tempo, no qual predominavam a imitação e os valores individuais,ora em decadência [...] a tipografia é o sinal dos novos tempos, dos novos valores, da igualdade entre os homens, que se efetiva nas trocas, no trabalho, nas artes, nas escolas, em toda parte.

Comênio destacou as vantagens do método da imprensa com relação à escrita a pena, ao descrever as possibilidades que a imprensa proporcionava para a publicização do livro e consequentemente da leitura. São elas:

- A rapidez da impressão: "dois rapazes podem imprimir mais exemplares de determinado livro, do que, no mesmo tempo, o faziam talvez duzentos copistas" (GASPARIN, 1994, p. 456).

- A perfeição da impressão: "os livros impressos são de tal maneira correspondentes uns aos outros que nem um ovo de galinha é tão semelhante a outro ovo" (GASPARIN, 1994, p. 456).

- A facilidade de correção: “corrigidas as provas tipográficas de um só exemplar, todos os outros, sejam eles quantos milhares forem, ficarão corrigidos" (GASPARIN, 1994, p. 456).

- A diversificação da matéria-prima: "pode imprimir-se em qualquer espécie de papel, mesmo sobre papiro muito fino e transparente, sobre linho, etc." (GASPARIN, 1994, p. 456).

- A simplificação do trabalho: "podem imprimir elegantemente livros [...] porque executam o trabalho, não com as próprias mãos, mas por meio de caracteres propositadamente preparados para isso" (GASPARIN, 1994, p. 456).

De acordo com Comênio (1985, p. 43), a nova forma universal de produzir correspondeu a uma nova forma universal de instruir, "segura, fácil e sólida", realizada com "economia de tempo e fadiga". O autor enumerou, 
ainda, as vantagens que a nova forma de instruir imprimia à vida material e intelectual, entre elas a publicação de livros, pois para Comênio, os professores, "mesmo aqueles que a natureza não dotou de muita habilidade para ensinar" uma vez que para o autor, "a missão de cada um "não é tanto tirar da própria mente o que deve ensinar, sobretudo comunicar e infundir na juventude uma erudição já preparada e com instrumentos também já preparados, colocados nas suas mãos" (COMÊNIO, 1985, p. 457). Assim, conclui com uma metáfora, comparando o professor a um organista que olha para partitura, "a qual talvez ele não fosse capaz de compor, nem de executar de cor só com a voz ou com o órgão", "assim também o professor há de ensinar na escola todas as coisas" (COMÊNIO, 1985, p. 457).

Entusiasmado com a possibilidade de "imprimir as ciências no espírito da mesma maneira que [...] é possível imprimi-las no papel com a tinta" (COMÊNIO, 1985, p. 457), o autor batiza a nova arte com o nome de "didacografia" e passa a descrevê-la, destacando a semelhança com a organização das manufaturas. Na didacografia, o papel são os alunos, em cujas mentes ficam impressas as marcas da ciência, os tipos, os livros didáticos e outros instrumentos que facilitam a aprendizagem rápida, a tinta, a voz do professor-mediador dos livros didáticos e os alunos e, finalmente, o prelo que é a disciplina escolar.

Segundo Alves (1993, p. 83), a didacografia é:

uma proposta indiscutivelmente burguesa e reflete o que há de mais desenvolvido em seu tempo. A divisão manufatureira do trabalho, que se aprofundou sobre a base técnica do artesanato, tem o seu correspondente, dentro do plano de comércio, na seriação dos estudos e na divisão das áreas de conhecimento. A aspiração do educador morávio é a de que a organização dê livre curso a um processo cuja dinâmica deve ter as mesmas características de um funcionamento de um autômato.

Enquanto a máquina tipográfica multiplicou os livros ao infinito, a didacografia ampliou a cultura e estendeu a instrução a um número maior de cidadãos; ambas fizeram do livro impresso a alavanca para universalizar o conhecimento e igualizar os homens em suas produções e possibilidades de acesso a essas produções. 
Em Didáctica Magna há inúmeras situações que evidenciam a preocupação de Comênio com a produção de livros e a sua utilização didática, o que nos permite afirmar que o tratamento do autor dispensado a este eficiente meio de comunicação patenteia o caráter de publicização da leitura em sua obra.

A seguir, elencamos algumas dessas situações que explicitam o caráter de publicização da leitura, como:

- A importância que o autor atribui ao livro impresso como veículo de um mesmo conhecimento a muitas pessoas: "descoberta a arte tipográfica, se multiplicaram os livros, veículos de instrução" (ALVES, 1993, p. 465).

- O tratamento dado ao conteúdo e à linguagem para adequar o livro à massificação da linguagem: "Estes livros, portanto, deverão ser conforme as nossas leis da facilidade, da solidez e da brevidade [...] e que exponham todas as coisas de modo familiar e popular, para que tornem tudo acessível aos alunos, de modo que o entendam, mesmo sem qualquer professor" (ALVES, 1993, p. 289).

- A elaboração de livros didáticos: "Os livros didáticos serão, portanto, de dois géneros: verdadeiros livros de textos para alunos, e livros roteiros (informatorii) para os professores para que aprendam a servir-se bem daqueles" (ALVES, 1993, p. 460).

- A confecção de livros auxiliares para o ensino de línguas: "Dá-se o nome de livros auxiliares àqueles que ajudam a usar, de uma maneira rápida, e com maior fruto, os livros didácticos" (ALVES, 1993, p. 339). São eles: “o vocabulário [...] para o Vestíbulo. Para a Porta, o dicionário etimológico latim-língua materna. Para o Palácio, o dicionário fraseológico língua materna-língua materna e [...] finalmente o Tesouro será auxiliado ou reforçado por um prontuário universal" (ALVES, 1993, p. 339).

- A montagem de livros-roteiros para os educadores: "é necessário dar normas, em conformidade com as quais executem as suas obras, isto é, devem escrever-se para uso deles Livros-Roteiros ao 
que hão-de fazer, em que lugar e de que modo, para que se não caia em erro" (ALVES, 1993, p. 460).

- A invenção de livros ilustrados: "outra coisa que poderá ser útil aos exercícios da escola materna será um livrinho de Imagens, a colocar nas mãos da própria criança [...] faz aprender a ler mais facilmente" (ALVES, 1993, p. 422).

- A criação de livros de aconselhamento para pais e amas: "compilar um livro de conselhos para os pais e amas, para que não ignorem os seus deveres. Neste livro, devem expor-se, uma por uma, todas as coisas em que é necessário formar a infância" (ALVES, 1993, p. 422).

- A adaptação de obras fundamentais, os livros de bolso: "para ensinar as artes e as línguas, como livros fundamentais devem escolher-se ou fazer-se de novo volumes de pequeno tamanho e de notável utilidade que exponham as coisas sumariamente" (ALVES, 1993, p. 294).

- A compilação de livros enciclopédicos para adolescentes: "Pensamos que será possível compilar, para cada classe, um livrinho especial, que contenha um certo género de fatos históricos, segundo o programa" (ALVES, 1993, p. 445).

- Os livros de textos para a escola de língua nacional: "a cada classe sejam destinados livros de textos próprios, que contenham todo o programa prescrito" (ALVES, 1993, p. 430).

- A impressão de livros pan-metódicos para pôr em prática seu método universal: "uma só coisa é de extraordinária importância, pois se ela falta, pode tornar-se inútil toda a máquina, ou se está presente, pode pô-la toda em movimento: uma provisão suficiente de livros pan-metódicos" (ALVES, 1993, p. 465).

Concluindo, sua obra foi construída gradativamente em meio às transformações sociais e sua arte de ensinar foi o resultado da longa trajetória do pedagogo, atravessada por determinações e mediações sociais, na transição do feudalismo para o capitalismo. De acordo com Comênio (1985, p. 464), com a descoberta da: 
arte tipográfica, se multiplicaram os livros, veículos de instrução, assim também, descoberta a didacografia ou método universal, é possível multiplicar os jovens instruídos, com grande proveito para a prosperidade das coisas humanas, segundo a máxima 'a multidão dos sábios é a salvação do mundo' (Sabedoria, 6, 26).

Enfim, incorporando o modelo dos manufatureiros, os avanços da ciência e da tecnologia, Comênio trouxe o mundo fabril para a escola, que foi para o autor uma oficina onde todos podiam ensinar e todos podiam aprender, aprender a ler e ensinar a ler. Assim, como a tipografia proporcionou a publicização do livro, a didacografia trouxe a publicização da leitura.

\section{Referências}

ALVES, G. L. O pensamento burguês no Seminário de Olinda. Ibitinga: Humanidades, 1993.

ARAÚJO, C. B.; ZANDAVALli, M. de. O professor na Didática Magna. Monografia (Mestrado em Educação) - Faculdade de Educação, Universidade Federal de Mato Grosso do Sul, Campo Grande, 1994.

BAKHTIN, M. Estética da criação verbal. São Paulo: Martins Fontes, 1992.

COMÊNIO, J. A. Didáctica Magna. 3. ed. Lisboa: Calouste Gulbenkiann, 1985.

GASPARIN, J. L. Comênio ou da arte de ensinar tudo a todos. Campinas: Papirus, 1994.

Data de registro:07/07/2011

Data de aceite:02/05/2012 